\title{
Potential use of chymotrypsin-like proteasomal activity as a biomarker for prostate cancer
}

\author{
XINGHUA WEI ${ }^{1,2^{*}}$, WEIWEI ZENG ${ }^{1,2^{*}}$, KEJI XIE ${ }^{2}$, PENGFEI DIAO ${ }^{2}$ and PING TANG ${ }^{1,2}$ \\ ${ }^{1}$ Department of Urology, The First Affiliated Hospital, Jinan University, Guangzhou, \\ Guangdong 510632; ${ }^{2}$ Department of Urology, Guangzhou First People's Hospital, \\ Guangzhou Medical University, Guangzhou, Guangdong 510180, P.R. China
}

Received September 30, 2016; Accepted December 8, 2017

DOI: $10.3892 / \mathrm{ol} .2018 .7936$

\begin{abstract}
Although it is the most widely used biomarker for prostate cancer, the use of prostate specific antigen (PSA) is controversial due to its limitations in specificity and sensitivity. The proteasome is a complex associated with cell proliferation and apoptosis, and the abnormity of these processes may lead to tumor occurrence. Previous studies have reported that proteasomal activity is associated with cancer progression and can be used in risk stratification. The purpose of the present study was thus to investigate the feasibility of proteasome activity as a biomarker for prostate cancer. Proteasome activity in vitro and in vivo was detected, along with the expression of the substrate proteins NF- $\kappa$ B inhibitor- $\alpha(\mathrm{I} \kappa \mathrm{B}-\alpha)$, Bcl-2-associated X (Bax) and p27. Chymotrypsin-like proteasomal activity was elevated by $70 \%$ in vitro and $23 \%$ in vivo, and the expression levels of the proteasome substrate proteins I $\mathrm{B}-\alpha, \mathrm{Bax}$ and p27 were decreased in prostate cancer cells and prostate tumor xenografts compared with normal mouse prostate tissue. In conclusion, proteasomal chymotrypsin-like activity maybe a potential biomarker for prostate cancer, and may be suitable to supplement PSA in clinical application for prostate cancer diagnosis.
\end{abstract}

\section{Introduction}

Prostate cancer is the most commonly diagnosed malignancy in men in western countries (1). As the second most common cause for cancer-associated mortality among men, prostate cancer caused 27,540 deaths in the United States (2015) (2).

Correspondence to: Dr Ping Tang, Department of Urology, The First Affiliated Hospital, Jinan University, 613 Huang Pu Road, Guangzhou, Guangdong 510632, P.R. China

E-mail: pingtang09@yahoo.com

*Contributed equally

Key words: prostate cancer, biomarker, proteasome, chymotrypsin-like activity, nuclear factor- $\kappa \mathrm{B}$ inhibitor- $\alpha$, B-cell lymphoma 2-associated X, p27
In addition, the incidence and mortality for prostate cancer have been evidently increasing in Asia, including in China, in recent years (3).

Although novel therapies for prostate cancer with proven survival benefits have been developed relatively recently $(4,5)$, the overall increase in survival rate has been negligible. A major clinical challenge in prostate cancer is the insufficient power of the currently available diagnostic tests. Since the introduction of serum prostate specific antigen (PSA) screening $>30$ years ago, prostate cancer diagnosis and management have been guided by this biomarker; it remains the most commonly used tumor marker for prostate cancer diagnosis, postoperative monitoring and prognosis evaluation. PSA is a protein secreted by the epithelial cells of the prostate; an increase in serum PSA is often identified in prostate cancer patients $(6,7)$. However, PSA is susceptible to various confounding factors, including benign prostatic hyperplasia, prostatitis and urethral surgery, which may influence the clinical reliability $(8,9)$. The deficiencies of PSA, including the lack of specificity and sensitivity, may lead to false-positive or false-negative results. In view of this, identifying a biomarker with an improved diagnostic and prognostic potential for prostate cancer assessment may be of great significance.

Refinements to PSA measurements have been proposed, including early PSA, benign PSA, free PSA, dynamic PSA parameters (including PSA velocity and PSA doubling time), PSA density (PSA to prostate volume ratio) and age-specific PSA level (1). Although these alternative applications of PSA may improve the diagnosis accuracy of prostate cancer to a certain extent, their relatively complicated implementation and the same confounding issues as usually affect tPSA continue to limit their application (10).

The proteasome is a multicatalytic proteinase complex responsible for the degradation of the majority of intracellular proteins, including the proteins required for cell cycle regulation and apoptosis (11). The $26 \mathrm{~S}$ proteasome is comprised of two $19 \mathrm{~S}$ regulatory subunits and a $20 \mathrm{~S}$ core. In the proteasome degradation system, the target protein is recognized by the $19 \mathrm{~S}$ subunits following ubiquitination, and can then access the $20 \mathrm{~S}$ core for further degradation. The $20 \mathrm{~S}$ subunit is a multicatalytic threonine protease with three types of enzymatic activity, described as chymotrypsin-like, trypsin-like and caspase-like activities. As part of the ubiquitin-proteasome pathway, the 
proteasome plays a vital role in the degradation of proteins from a broad range of cellular pathways, and contributes to the pathology of a number of human diseases, including cancer, in which regulatory proteins may be stabilized due to decreased degradation, or lost due to accelerated degradation (12). The proteasome degrades a range of endogenous proteins associated with cancer, including transcription factors, cyclins, Bcl-2-associated X (Bax), p53, p27 and inhibitor of $\mathrm{NF} \kappa \mathrm{B}-\alpha(\mathrm{I} \kappa \mathrm{B}-\alpha)$, and it has become an important potential target for cancer therapy.

The majority of studies regarding this topic have concentrated on the proteasome inhibitor for tumor treatment; research on the proteasome for disease diagnosis is insufficient. Stoebner et al (13) reported that in 20 tumor patients (including those with breast, gastric, kidney, colon, testicular, liver and lung cancer), the proteasome 20S serum level was significantly elevated compared with controls, indicating serum proteasome could be applied in tumor diagnostics. Our previous study demonstrated that a proteasome inhibitor could affect the proliferation and apoptosis of prostate cancer cells by inhibiting chymotrypsin-like activity, thus influencing the expression of the target proteins I $\mathrm{B}-\alpha$, Bax and p27 (14). Therefore, in the present study, the chymotrypsin-like, trypsin-like and caspase-like proteasomal activity in cultured LnCaP cells and tumor-bearing nude mice was assessed, in addition to the expression of the proteasomal substrates I $\mathrm{B}-\alpha$, Bax and p27, in order to analyze the feasibility of proteasomal activity as a candidate biomarker for prostate cancer.

\section{Materials and methods}

Materials. LNCaP human prostate cells were provided by Ryder Guanzhou Lian Kang Biological Technology Co., Ltd. (Guangzhou, China). A Prostate Epithelial Cell Medium BulletKit ${ }^{\mathrm{TM}}$ was purchased from Lonza Group, Ltd. (Basel, Switzerland). The keratinocyte-serum free medium was purchased from Gibco (Thermo Fisher Scientific, Inc., Waltham, MA, USA) and PBS was from Hyclone (GE Healthcare Life Sciences, Logan, UT, USA). RPMI-1640, penicillin and streptomycin were purchased from Invitrogen (Thermo Fisher Scientific, Inc.). Fetal bovine serum (FBS) was purchased from Hyclone (GE Healthcare Life Sciences). Mouse monoclonal antibodies against Bax (cat. no. sc-23959) and p27 (cat. no. sc-1641), and rabbit polyclonal antibodies against inhibitor of nuclear factor (NF)- $\mathrm{B}-\alpha(\mathrm{I} \kappa \mathrm{B}-\alpha$; cat. no. sc-203) and GAPDH (FL-335; cat. no. sc-25778) were both from Santa Cruz Biotechnology, Inc. (Dallas, TX, USA). Suc-LLVY-AMC, Z-LLE-NA, and BZVGR-AMC was all from Sigma-Aldrich; Merck KGaA (Darmstadt, Germany).

Cell culture. LNCaP cells were grown in RPMI-1640 supplemented with $10 \% \mathrm{FBS}, 100 \mathrm{U} / \mathrm{ml}$ of penicillin and $100 \mu \mathrm{g} / \mathrm{ml}$ of streptomycin, and were maintained at $37^{\circ} \mathrm{C}$ and $5 \% \mathrm{CO}_{2}$ for 1 week. Prostate epithelial cells were obtained from prostate tissue by conventional tissue culture methods: A human prostate tissue specimen was obtained from men undergoing robotic radical prostatectomy, and was sliced into $1 \mathrm{~mm}^{3}$ blocks and placed in a T25 flask coated with collagen. The tissue blocks were cultured at $37^{\circ} \mathrm{C}$ with $5 \% \mathrm{CO}_{2}$ for $\sim 1$ week in prostate epithelial cell medium, and the medium was changed every 3 days. The cells were digested and collected when the primary monolayer cells covered the surface of the flask, and they were passaged with keratinocyte-serum free medium. The first generation of cells were used for further experiments to ensure the integrity of the prostate epithelial cells. Cells were observed for morphological changes and photographed under a phase contrast inverted microscope (magnification, x100; Olympus Corporation, Tokyo, Japan). The use of human tissue was approved by the Research Ethics Committee of Guangzhou First People's Hospital, Guangzhou Medical University (Guangdong, China), and written informed consent from the patient was acquired prior to the use of the tissue in research.

Human prostate tumor xenograft experiments. Animal experiments in the present study were performed in accordance with the guidelines outlined by the Institute for Laboratory Animal Research in Guangzhou Medical University (Guangzhou, China). A total of 30 male BALB/C-nu mice aged 4-6 weeks, (mean body weight, $20 \mathrm{~g}$ ) were purchased from Guangdong Medical Laboratory Animal Center (Foshan, China) and housed in accordance to a protocol described previously (15). Mice were randomly divided into two groups (15 mice/group). In the experimental group, $5 \times 10^{5} \mathrm{LNCaP}$ cells suspended in $0.2 \mathrm{ml}$ PBS were inoculated into the left flank of each mouse. Mice in the control group were injected with $0.2 \mathrm{ml}$ PBS. Tumor sizes were measured every 3 days using calipers, and tumor volumes were calculated according to the standard formula: Width $^{2} \mathrm{x}$ length $\mathrm{x} 0.52$. At 4 weeks, the mice were sacrificed. Blood and tumor tissues were taken for further analysis.

Proteasome activities assay. $100 \mu \mathrm{l}$ suspension LNCaP cells $\left(1.0 \times 10^{5}\right.$ cells $\left./ \mathrm{ml}\right)$ and prostate epithelial cells $\left(1.0 \times 10^{5}\right.$ cells $\left./ \mathrm{ml}\right)$ were plated in a 96-well plate and cultured for $24 \mathrm{~h}$. Then $1 \mu \mathrm{l}$ of proteasome activity assay buffer containing $4 \mathrm{mM}$ a fluorogenic peptide substrate, including Suc-LLVY-AMC for detecting chymotrypsin-like activity, Z-LLE-NA for detecting caspase-like activity or BZVGR-AMC for detecting trypsin-like activity, was added to the wells. Following a $2 \mathrm{~h}$ incubation, the fluorescence intensity was measured by a microplate reader with the excitation wavelength of $380 \mathrm{~nm}$ and the emission wavelength of $460 \mathrm{~nm}$.

For the serum assay, $1 \mu \mathrm{l}$ containing $4 \mathrm{mM}$ of a fluorescent substrate was added to $100 \mu \mathrm{l}$ of mouse serum and incubated at $37^{\circ} \mathrm{C}$ for $2 \mathrm{~h}$. The proteasome activity was then detected as the fluorescence intensity by the microplate reader, with the excitation and emission wavelengths of 380 and $460 \mathrm{~nm}$, respectively.

Western blot analysis. Cells were harvested, washed with PBS twice and lysed in cell lysis buffer $(50 \mathrm{mM}$ Tris- $\mathrm{HCl} ; 150 \mathrm{mM}$ $\mathrm{NaCl} ; 1$ mM EDTA; $1 \%$ Triton X-100; 0.5\% Na-deoxycholate; $0.1 \%$ SDS; $1 \mathrm{mM}$ PMSF; $10 \mu \mathrm{l} / \mathrm{ml}$ protease inhibitor cocktail P8340 provided by Sigma-Aldrich; Merck KGaA) for 30 min at $4^{\circ} \mathrm{C}$. Then the cells were scraped off and transferred into a $1.5 \mathrm{ml}$ centrifuge tube. The lysates were centrifuged at $14,000 \times \mathrm{g}$ for $5 \mathrm{~min}$ at $4^{\circ} \mathrm{C}$. The DC ${ }^{\mathrm{TM}}$ Protein Assay kit II (cat. no. 5000112; Bio-Rad Laboratories, Inc., Hercules, CA, USA) was used to determine the protein concentration 
with the Bradford assay method, as follows: Standards from 0 to $4 \mathrm{mg} / \mathrm{ml}$ protein were prepared; $20 \mu \mathrm{l}$ of reagent $\mathrm{S}$ from the kit was added to $1 \mathrm{ml}$ reagent $\mathrm{A}$ and mixed thoroughly. Then $5 \mu \mathrm{l}$ of each standard and sample solution was added into $25 \mu \mathrm{l}$ of the S/A mixture in separate microtiter plate wells. Next, $200 \mu \mathrm{l}$ of reagent B was added, and the wells were mixed thoroughly using a micro plate mixer. Following incubation at room temperature for $15 \mathrm{~min}$, the absorbance was measured at $750 \mathrm{~nm}$ in a plate reader. Then $50 \mu \mathrm{g}$ of cell lysates were separated using SDS-PAGE (10\% gel) and electrophoretically transferred to a PVDF membrane, followed by western blotting using the aforementioned specific antibodies to I $\mathrm{B}-\alpha$, Bax, p27 and GAPDH, as previously described (16). Images were then visualized using an enhanced chemiluminescence kit (cat. no. 32106; Pierce, Rockford, IL USA) and quantified using ImageJ software (version 1.48; National Institutes of Health, Bethesda, MD, USA). Benign gross prostate tissues from the mice in the control group were obtained, as described by a previous protocol (17). Western blotting using the tumor and benign prostate tissue samples from the mice was then performed as for the cultured cancer cells.

Statistical analysis. SPSS (version 18; SPSS, Inc., Chicago, IL, USA) was used for data analysis. Student's t-test was applied to evaluate the differences between the experimental and control groups. Data were expressed as the mean \pm standard deviation (SD), and results from at least three independent experiments were used for statistical analysis. All statistical tests were two-sided. $\mathrm{P}<0.01$ was considered to indicate a statistically significant difference.

\section{Results}

Isolation of prostate epithelial cells from prostate tissues. Prostate epithelial cells were obtained from prostate tissue by conventional tissue culture methods. On observation, cells were identified to be well adhered to the collagen surface with a good growth state (Fig. 1A). The prostate epithelial cells exhibited epithelium-like morphology and enhanced cell viability, overspreading the bottom of the flask at the 16th day. Subsequent to the formation of a cell monolayer, cells were passaged with Keratinocyte-SFM medium (Fig. 1B). The first generation of cells was used for further experiment.

Establishment of a prostate cancer model in mice. At 4 days after the inoculation of LNCaP cells into nude mice, the formation of tumors started to be observed. At the end of the experiment (day 29), the mean size of the tumors was $350 \mathrm{~mm}^{3}$ (Fig. 2). The mice were then sacrificed, and blood and tumor tissues were collected for further assays. Thus, a mouse model for prostate cancer was established.

Proteasomal chymotrypsin-like activity of LNCaP cells

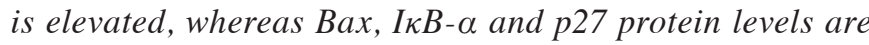
decreased. Previous reports have demonstrated an elevated proteasome level in patients with myeloid hematopoietic malignancies (18-20), solid tumors (19) and autoimmune diseases (21). To determine the proteasomal activity variation at acellular level, the proteasomal chymotrypsin-like, caspase-like and trypsin-like activities were measured in
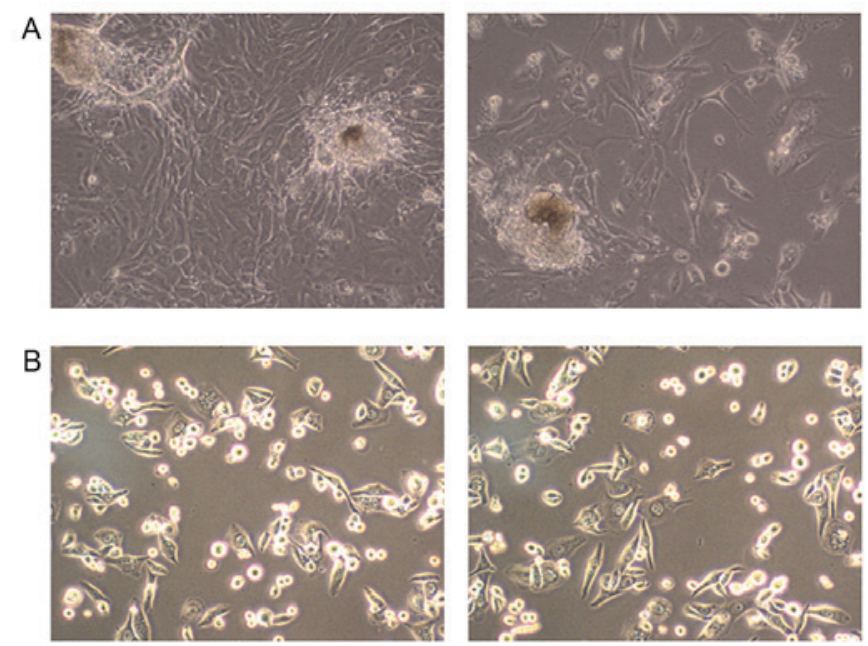

Figure 1. Microscopy images of prostate epithelial cells obtained from human prostate tissue by conventional tissue culture methods. (A) Cells were isolated from prostate tissues in prostate epithelial cell medium and incubated to form a cell monolayer. (B) Prostate epithelial cells were harvested from the monolayer and subcultivated in keratinocyte-serum free medium. Original magnification, $\mathrm{x} 100$.

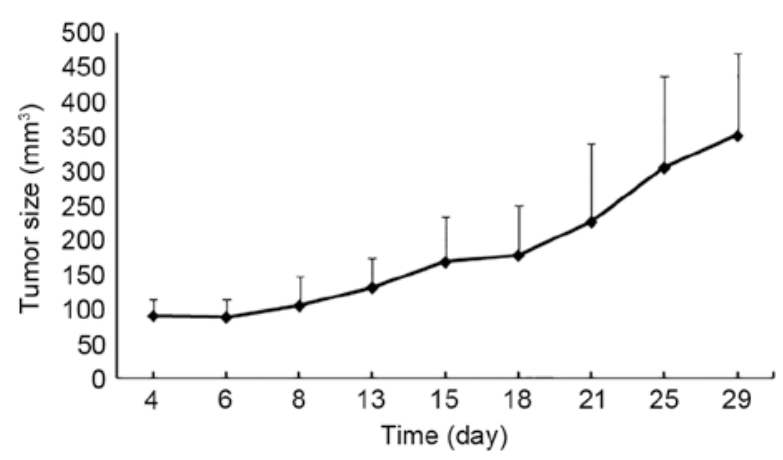

Figure 2. Size of tumors in LNCaP cell-inoculated mice. The growth of tumors was observed from day 4 . The mean size of the tumors reached $350 \mathrm{~mm}^{3}$ at the end of the experiment. $n=15$, data are presented as mean \pm standard deviation (SD).

LNCaP prostate cancer and normal epithelial prostate cells four times. The proteasomal chymotrypsin-like activity was elevated by $\sim 70 \%$ in LNCaP cells compared with prostate epithelial cells $(3,286 \pm 259.01$ vs. $1,080 \pm 100.13 ; \mathrm{P}<0.01)$. Caspase-like activity was decreased in LNCaP cells $(\mathrm{P}<0.01)$, whereas trypsin-like proteasomal activity was not significantly altered (Fig. 3A). The expression levels of three of the most important proteasomal target proteins, Bax, IкB- $\alpha$, and p27 $(22,23)$, were then assessed by western blotting. The results indicated all three of the proteins were markedly reduced in LNCaP cells when compared with PE cells $(\mathrm{P}<0.01$; Fig. $3 \mathrm{~B}$ and $\mathrm{C}$ ), which was consistent with a previous study (14).

Chymotrypsin-like activity is increased in xenografts compared with normal mouse prostate tissue, accompanied by a reduced Bax, I $\kappa$ - $\alpha$ and $p 27$ protein level. In order to clarify whether the chymotrypsin-like proteasomal activity was also elevated in vivo, the serum of the mice with or without LNCaP prostate cancer cell xenografts was collected for proteasome activity assays. The chymotrypsin-like 

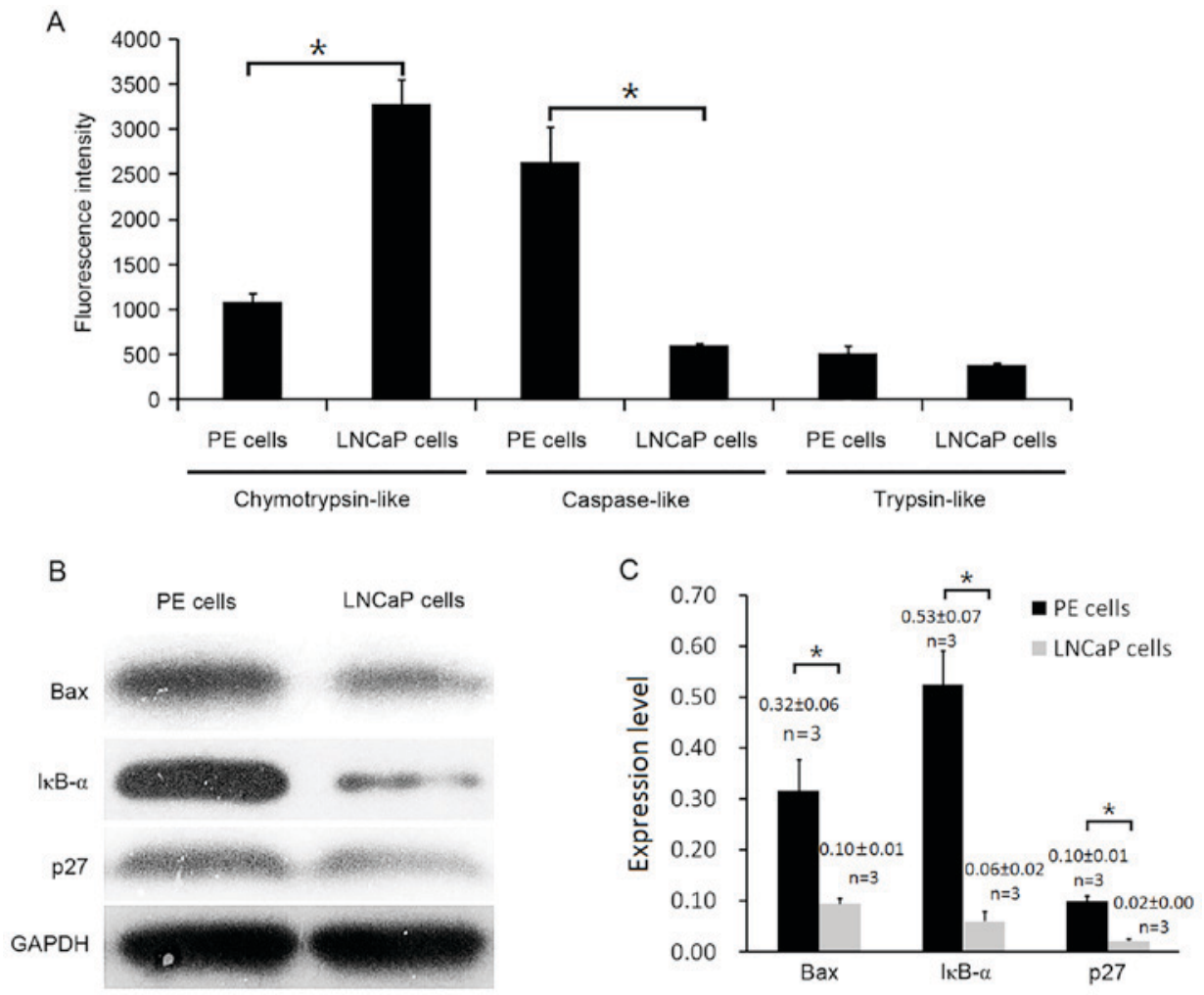

Figure 3. Proteasomal activity in vitro. (A) Chymotrypsin-like, caspase-like and trypsin-like activity of the proteasome was measured in LNCaP and prostate epithelial cells. Chymotrypsin-like and caspase-like activities were significantly different between the LNCaP and prostate epithelial cells. Data are presented as means \pm standard deviation. ${ }^{*} \mathrm{P}<0.01$. (B) Representative images of western blotting to determine the expression of Bax, I $\mathrm{KB}-\alpha$ and $\mathrm{p} 27$ in $\mathrm{LNCaP}$ cells compared with prostate epithelial cells, with GAPDH as a loading control. (C) Quantified western blotting results. Each bar represents the mean of three independent experiments; data are expressed as mean \pm standard deviation (SD). "P $<0.01$. Bax, Bcl-2-associated X; IкB- $\alpha, \mathrm{NF}-\kappa \mathrm{B}$ inhibitor- $\alpha$.

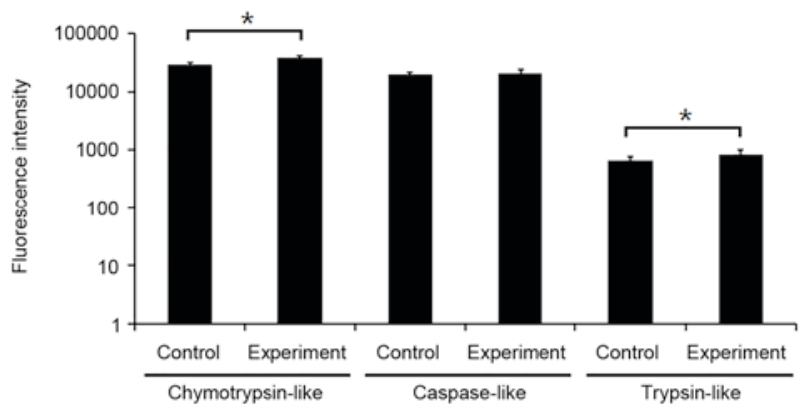

Figure 4. Chymotrypsin-like, caspase-like and trypsin-like proteasomal activity in mouse serum. Chymotrypsin-like and trypsin-like activities were statistically different between xenograft-bearing mice and control mice, whereas caspase-like activity was equivalent. Data are presented as means \pm standard deviation. ${ }^{*} \mathrm{P}<0.01$.

activity of the serum in tumor bearing mice was increased by $23 \%(37,344.67 \pm 2,719.64$ vs. $28,845.87 \pm 1,880.47 ; \mathrm{P}<0.01)$ compared with the control mice, which was in accord with the in vitro results. In addition, the trypsin-like activity was elevated by $21 \%(824.53 \pm 164.87$ vs. $648 \pm 97.5, \mathrm{P}<0.01$; Fig. 4$)$ in the experimental mice, whereas the caspase-like activity of the two groups was at a similar level (Fig. 4). Furthermore, the protein levels of $\mathrm{Bax}, \mathrm{I} \kappa \mathrm{B}-\alpha$ and p27 were analyzed in three pairs of tumor bearing and normal mice using western blot analysis. Decreased levels of Bax, I $\mathrm{B}-\alpha$ and p27 protein were observed in the mouse tumor tissue compared with the prostate tissue from the control mice ( $\mathrm{P}<0.01$; Fig. $5 \mathrm{~A}$ and $\mathrm{B})$.
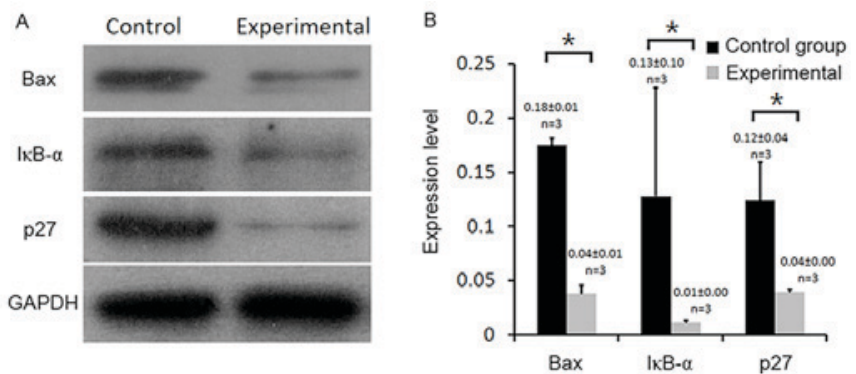

Figure 5. Expression of Bax, I $\mathrm{KB}-\alpha$, and $\mathrm{p} 27$ protein in vivo. (A) Representative images of western blotting to determine the expression of Bax, IкB- $\alpha$ and p27 in the mouse tumor tissue and the prostate tissue from the control mice. Tumor tissue was removed on day 29 for analysis by western blotting. Decreased Bax, IкBa, and p27 protein levels were observed in the tumor tissues, with GAPDH as a loading control. (B) Quantified western blotting results. Three mice were selected from each group for this assay. Each bar represents the mean of three independent experiments; data were expressed as the mean \pm standard deviation (SD). ${ }^{*} \mathrm{P}<0.01$. Bax, Bcl-2-associated $\mathrm{X}$; IкB- $\alpha$, NF- $\kappa$ B inhibitor- $\alpha$.

\section{Discussion}

Prostate cancer is a worldwide concern with a rising incidence and mortality rate $(3,24,25)$; PSA has been used as a biomarker for prostate cancer since the 1980s, although its use remains controversial due to its lack of specificity. Previous studies have reported that increased chymotrypsin-like proteasomal activity is associated with various types of tumor, 
including acute myeloid leukemia (26) and melanoma (13). In the present study, the chymotrypsin-like proteasomal activity was significantly elevated $(\mathrm{P}<0.01)$ in prostate cancer cells and tumor-bearing mice compared with normal epithelial prostate cells and control mice, suggesting that chymotrypsin-like proteasomal activity may be a candidate biomarker to supplement PSA in the diagnosis of prostate cancer. As the inherent limitations of PSA may cause over-diagnosis, leading to the over-treatment of prostate cancer and causing psychological distress, loss of bodily function, pain and suffering for patients (27), improving the sensitivity and specificity of the detection of prostate cancer is critical. The chymotrypsin-like proteasomal activity assay is relatively simple and reproducible, and can be performed on peripheral blood plasma. Therefore, achymotrypsin-like activity assay together with PSA detection could potentially enhance the accuracy of PSA for prostate cancer diagnosis, ultimately reducing the pain and burden for patients.

Although previous studies $(18,19,26)$ have demonstrated that plasma proteasomes may act as a biomarker in several types of tumor, the origin of the proteasomal activity is has not been identified. Deng et al (28) hypothesized that the aggressiveness of prostate cancer could be a mechanism; highly malignant cells escape more frequently into the circulation system, and the chymotrypsin-like proteasomal activity in the serum could become elevated with the increase of these cells and their tumor-specific products. This hypothesis is in accord with the increased chymotrypsin-like activity in the $\mathrm{LnCaP}$ cell medium and the tumor-bearing mice serum in the present study. In addition, the caspase-like and trypsin-like activity at both the cell culture and serum level were altered, as the caspase-like activity was significantly decreased in the cell experiments, whereas the trypsin-like activity was elevated in the tumor-bearing mouse serum, implying that the activity of the proteasomal pathway maybe altered during, or as a result of, tumorigenesis and progression.

In the present study, the expression of proteasome target proteins was also assessed, including p27, which functions in cell cycle progression; Bax, which is associated with apop-

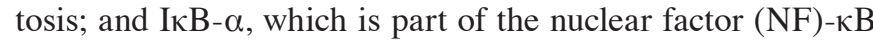
pathway (29). The expression levels of all three substrates were decreased in prostate cancer cells and xenograft tumor tissue in the present study. The elevated chymotrypsin-like activity may have induced the degradation of these tumor suppressor proteins, ultimately leading to a greater resistance to apoptosis, and more aggressive cancer behavior. As an inhibitor of $\mathrm{NF}-\kappa \mathrm{B}$, the degradation of $\mathrm{I} \kappa \mathrm{B}-\alpha$ by the proteasome facilitates the translocation of $\mathrm{NF}-\kappa \mathrm{B}$ into the nucleus and thus promotes cell survival (30), resulting in the reduced effectiveness of anticancer therapy $(31,32)$. A relatively low level of p27 is frequently detected in human tumors, and the degradation of p27 by the proteasome may result in uncontrolled cell division, ultimately leading to transformation and tumor development (33). The degradation of Bax has been identified in aggressive human prostate cancer, which corresponds with the results of the present study (34). As a Bcl-2 family member, Bax is a critical molecule upstream of intrinsic cellular apoptosis; its degradation contributes to maintaining cancer cell survival (35). It has been reported that the inhibition of chymotrypsin-like proteasome activity may lead to the accumulation of $\mathrm{I} \kappa \mathrm{B}-\alpha$, Bax and p27 in different types of cancer cell and tumor models (14), followed by the induction of cell death. Therefore, proteasome inhibitors that target chymotrypsin-like activity may be a potential strategy for prostate cancer treatment.

There are some limitations to the present study. Firstly, this research detected the proteasomal chymotrypsin-like activity in cell culture and xenografts, and not in clinical samples from prostate cancer patients. As a proof of concept, the present study provided some data to suggest that chymotrypsin-like activity is a potential candidate biomarker for prostate cancer, and may build a foundation for future study. Further work to validate the data of the present study for patients with prostate cancer will be required. Secondly, proteasomal chymotrypsin-like activity is not a specific marker for prostate cancer; it is likely to be increased in various types of carcinoma (36-38). Therefore, elevated chymotrypsin-like activity cannot independently indicate the occurrence of prostate cancer; however, it may improve the accuracy of prostate cancer diagnosis when used in conjunction with increased PSA level, thus decreasing the chances of over-diagnosis and over-treatment for patients with suspected prostate cancer.

Ma et al (26) reported that the chymotrypsin-like activity in plasma may provide a powerful biomarker for the risk stratification of acute myeloid leukemia and advanced-stage myelodysplastic syndrome, which provides a novel perspective on the application of chymotrypsin-like activity as a cancer biomarker. Further studies will be required to verify whether this serological test may serve as a prognostic factor to detect disease progression in patients with prostate cancer.

\section{Acknowledgements}

Not applicable.

\section{Funding}

The present study was supported by Guangzhou General Science and Technology Project of Health and Family Planning (no. 20161A011011) to Xinghua Wei.

\section{Availability of data and materials}

The authors confirm that all data underlying the findings are fully available without restriction.

\section{Authors' contributions}

Conceived and designed the experiments: PT. Performed the experiments: XW and WZ. Analyzed the data: KX and PF. Contributed reagents/materials/analysis tools: PT. Contributed to the writing of the study: XW and PT.

\section{Ethics approval and consent to participate}

The use of human tissue was approved by the Research Ethics Committee of Guangzhou First People's Hospital, Guangzhou Medical University (Guangdong, China), and written informed consent from the patient was acquired prior to the use of the tissue in research. 


\section{Consent for publication}

Written informed consent from the patient was acquired prior to the use of the tissue in research.

\section{Competing interests}

The authors declare that they have no competing interests.

\section{References}

1. Saini S: PSA and beyond: Alternative prostate cancer biomarkers Cell Oncol (Dordr) 39: 97-106, 2016.

2. Siegel RL, Miller KD and Jemal A: Cancer statistics, 2015. CA Cancer J Clin 65: 5-29, 2015.

3. Lei T, Mao WM, Yang HJ, Chen XZ, Lei TH, Wang XH, Ying Q, Chen WQ and Zhang SW: Study on cancer incidence through the cancer registry program in 11 cities and counties, China. Zhonghua Liu Xing Bing Xue Za Zhi 30: 1165-1170, 2009 (In Chinese).

4. Fong MK, Hare R and Jarkowski A: A new era for castrate resistant prostate cancer: A treatment review and update. J Oncol Pharm Pract 18: 343-354, 2012.

5. Rodrigues DN, Butler LM, Estelles DL and de Bono JS Molecular pathology and prostate cancer therapeutics: From biology to bedside. J Pathol 232: 178-184, 2014.

6. Lilja H: Testing new PSA subforms to enhance the accuracy of predicting cancer risk and disease outcome in prostate cancer. Clin Chem 54: 1248-1249, 2008.

7. Lilja H, Ulmert D and Vickers AJ: Prostate-specific antigen and prostate cancer: Prediction, detection and monitoring. Nat Rev Cancer 8: 268-278, 2008.

8. Romero Otero J, Garcia Gomez B, Campos Juanatey F and Touijer KA: Prostate cancer biomarkers: An update. Urol Oncol 32: 252-260, 2014

9. Cary KC and Cooperberg MR: Biomarkers in prostate cancer surveillance and screening: Past, present, and future. Ther Adv Urol 5: 318-329, 2013

10. Prensner JR, Rubin MA, Wei JT and Chinnaiyan AM: Beyond PSA: The next generation of prostate cancer biomarkers. Sci Transl Med 4: 127rv3, 2012.

11. Voorhees PM, Dees EC, O'Neil B and Orlowski RZ: The proteasome as a target for cancer therapy. Clin Cancer Res 9: 6316-6325, 2003.

12. Ciechanover A: The ubiquitin-proteasome pathway: On protein death and cell life. EMBO J 17: 7151-7160, 1998

13. Stoebner PE, Lavabre-Bertrand T, Henry L, Guiraud I, Carillo S, Dandurand M, Joujoux JM, Bureau JP and Meunier L: High plasma proteasome levels are detected in patients with metastatic malignant melanoma. Br J Dermatol 152: 948-953, 2005.

14. Yang H, Zhou P, Huang H, Chen D, Ma N, Cui QC, Shen S, Dong W, Zhang X, Lian W, et al: Shikonin exerts antitumor activity via proteasome inhibition and cell death induction in vitro and in vivo. Int J Cancer 124: 2450-2459, 2009.

15. Piantanelli L, Zaia A, Rossolini G, Piantanelli A, Basso A and Anisimov VN: Long-live euthymic BALB/c-nu mice. I. Survival study suggests body weight as a life span predictor. Mech Ageing Dev 122: 463-475, 2001.

16. An B, Goldfarb RH, Siman R and Dou QP: Novel dipeptidyl proteasome inhibitors overcome $\mathrm{Bcl}-2$ protective function and selectively accumulate the cyclin-dependent kinase inhibitor p27 and induce apoptosis in transformed, but not normal, human fibroblasts. Cell Death Differ 5: 1062-1075, 1998.

17. Harmelin A, Danon T, Kela I and Brenner O: Biopsy of the mouse prostate. Lab Anim 39: 215-220, 2005.

18. Wada M, Kosaka M, Saito S, Sano T, Tanaka K and Ichihara A Serum concentration and localization in tumor cells of proteasomes in patients with hematologic malignancy and their pathophysiologic significance. J Lab Clin Med 121: 215-223, 1993.
19. Lavabre-Bertrand T, Henry L, Carillo S, Guiraud I, Ouali A, Dutaud D, Aubry L, Rossi JF and Bureau JP: Plasma proteasome level is a potential marker in patients with solid tumors and hemopoietic malignancies. Cancer 92: 2493-2500, 2001.

20. Dutaud D, Aubry L, Henry L, Levieux D, Hendil KB, Kuehn L, Bureau JP and Ouali A: Development and evaluation of a sandwich ELISA for quantification of the $20 \mathrm{~S}$ proteasome in human plasma. J Immunol Methods 260: 183-193, 2002.

21. Egerer K, Kuckelkorn U, Rudolph PE, Rückert JC, Dörner T, Burmester GR, Kloetzel PM and Feist E: Circulating proteasomes are markers of cell damage and immunologic activity in autoimmune diseases. J Rheumatol 29: 2045-2052, 2002.

22. Goldberg AL: Functions of the proteasome: The lysis at the end of the tunnel. Science 268: 522-523, 1995.

23. Dou QP and Li B: Proteasome inhibitors as potential novel anticancer agents. Drug Resist Updat 2: 215-223, 1999.

24. Siegel R, Ma J, Zou Z and Jemal A: Cancer statistics, 2014. CA Cancer J Clin 64: 9-29, 2014.

25. Heidenreich A, Bastian PJ, Bellmunt J, Bolla M, Joniau S, van der Kwast T, Mason M, Matveev V, Wiegel T, Zattoni F, et al: EAU guidelines on prostate cancer. Part 1: Screening, diagnosis and local treatment with curative intent-update 2013. Eur Urol 65: 124-137, 2014.

26. Ma W, Kantarjian H, Bekele B, Donahue AC, Zhang X, Zhang ZJ, O'Brien S, Estey E, Estrov Z, Cortes J, et al: Proteasome enzymatic activities in plasma as risk stratification of patients with acute myeloid leukemia and advanced-stage myelodysplastic syndrome. Clin Cancer Res 15: 3820-3826, 2009.

27. Fowler FJ Jr, Barry MJ, Walker-Corkery B, Caubet JF, Bates DW, Lee JM, Hauser A and McNaughton-Collins M: The impact of a suspicious prostate biopsy on patients' psychological, socio-behavioral, and medical care outcomes. J Gen Intern Med 21: 715-721, 2006.

28. Deng X, Zhou P, Wei X, Uhlman M, Lin Y, Lin X, Wu S, Diao P, Xie H, Liu J, et al: Plasma proteasomal chymotrypsin-like activity correlates with prostate cancer progression. Tumour Biol 36: 4115-4121, 2015.

29. Frankland-Searby S and Bhaumik SR: The 26S proteasome complex: An attractive target for cancer therapy. Biochim Biophys Acta 1825: 64-76, 2012.

30. Adams J: The proteasome: Structure, function, and role in the cell. Cancer Treat Rev 29 (Suppl 1): S3-S9, 2003.

31. Jeremias I, Kupatt C, Baumann B, Herr I, Wirth T and Debatin KM: Inhibition of nuclear factor kappaB activation attenuates apoptosis resistance in lymphoid cells. Blood 91: 4624-4631, 1998.

32. Patel NM, Nozaki S, Shortle NH, Bhat-Nakshatri P, Newton TR, Rice S, Gelfanov V, Boswell SH, Goulet RJ Jr, Sledge GW Jr and Nakshatri H: Paclitaxel sensitivity of breast cancer cells with constitutively active NF-kappaB is enhanced by IkappaBalpha super-repressor and parthenolide. Oncogene 19: 4159-4169, 2000.

33. Chen D and Dou QP: The ubiquitin-proteasome system as a prospective molecular target for cancer treatment and prevention. Curr Protein Pept Sci 11: 459-470, 2010.

34. Almond JB and Cohen GM: The proteasome: A novel target for cancer chemotherapy. Leukemia 16: 433-443, 2002.

35. Li B and Dou QP: Bax degradation by the ubiquitin/proteasome-dependent pathway: Involvement in tumor survival and progression. Proc Natl Acad Sci USA 97: 3850-3855, 2000.

36. Kondakova IV, Spirina LV, Koval VD, Shashova EE, Choinzonov EL, Ivanova EV, Kolomiets LA, Chernyshova AL, Slonimskaya EM, Usynin EA and Afanasyev SG: Chymotripsin-like activity and subunit composition of proteasomes in human cancers. Mol Biol (Mosk) 48: 444-451, 2014.

37. Oldziej A, Bolkun L, Galar M, Kalita J, Ostrowska H, Romaniuk W and Kloczko J: Assessment of proteasome concentration and chymotrypsin-like activity in plasma of patients with newly diagnosed multiple myeloma. Leuk Res 38: 925-930, 2014.

38. Krawczuk-Rybak M, Leszczynska E, Malinowska I, Matysiak M and Ostrowska H: Proteasome chymotrypsin-like activity in plasma as a useful marker for children with acute lymphoblastic leukemia. Scand J Clin Lab Invest 72: 67-72, 2012. 